\title{
PRENATAL ULTRASOUND DIAGNOSIS OF DISCORDANT OCCIPITAL ENCEPHALOCELE IN MULTIPLE PREGNANCY - A CASE REPORT.
}

\author{
*O.U Ogbeide (MBBS, FMCR), *EJ IKUBOR (MBBS) \\ *Department of Radiology University of Benin Teaching Hospital, Benin-City, Nigeria
}

Correspondence:

Dr Ogbeide Osesogie Usuale

Department of Radiology

University of Benin Teaching Hospital,

Benin-City, Nigeria

\section{SUMMARY}

Background: Pre-natal sonographic examination is the primary modality of imaging in pregnancy which allows direct, real-time assessment of the fetus, and accurate diagnosis of congenital anomalies. One such anomaly is encephalocele.

Case Report:The case of a 38 year old gravida 14, Para 13+1 with a diagnosis of discordant encephalocele multiple (twin) pregnancy made during routine

sonographic examination is presented. One twin showed showed an occipital skull defect in association with a sonolucent area with well-defined margins continuous with the fetal scalp. There were no other associated anomalies.

Conclusion:Caution must be taken when performing a pre-natal sonographic examination to rule out congenital anomalies. This is important for the management of the pregnancies.

KEYWORDS: Ultrasonography, Intrauterine twin pregnancy, Encephalocele

\section{INTRODUCTION}

Encephalocele is a mesodermal defect in the skull bones and dura which may be associated with herniation of the brain tissues, meninges and cerebrospinal fluid. It is termed cranial meningocele if there is herniation of the meninges and cerebrospinal fluid only. ${ }^{1-2}$
The prevalence is about $1-4: 10,000$ live births and $5-20 \%$ of all craniospinal malformations and forms the predominant neural axis anomaly in fetuses spontaneously aborted less than 20 weeks gestational age. Hypothesis for the deficiency include failure of surface ectoderm to separate from neuro-ectoderm in early embryonic development. ${ }^{3}$

Patients with this lesion can present with pulsating exophthalmos and often have neurofibromatosis as their basic underlying problem.

The purpose of this paper is to present a case of occipital encephalocele diagnosed by prenatal ultrasonography and to highlight the sonographic appearances that enable accurate and early diagnosis.

\section{Case Report}

SA is a 38 year old gravida 14, Para $13^{+1}$ with five alive, lady referred from an urban maternity in Edo State to the antenatal centre of the University of Benin Teaching Hospital for a prenatal scan. Patient was not sure of her last menstrual period.

Her last childbirth 18 months earlier was a normal baby. She had a positive family history of multiple pregnancies. There was no family history of stillbirths or history of drug ingestion during pregnancy.

On examination her general physical condition was normal. Her fundal height corresponded to 28 weeks of




gestation. The fetal heart rate was 158 beats/min and 140 beats/min for each twin respectively. Her haemoglobin was $12 \mathrm{mg} \%$ and urinalysis was normal.

On ultrasound examination, twin intrauterine gestation both showing normal cardiac and fetal activity in longitudinal lie and normal flexion attitude was demonstrated. The amniotic fluid index was normal.
Placentation was separate having anterior and posterior components. There was no previa. Presentation of Twin 1 was cephalic and showed an occipital skull defect and an associated overlying sonolucent defect with welldefined margins continuous with the fetal scalp. There were no other associated anomalies such as ventriculomegaly or meningomyeloceles. (Figures $1 \& 2$ )

Figure 1: Sonogram of the longitudinal section of the fetal skull showing a defect in the occipital bone associated with an overlying anechoic cyst and well defined walls.



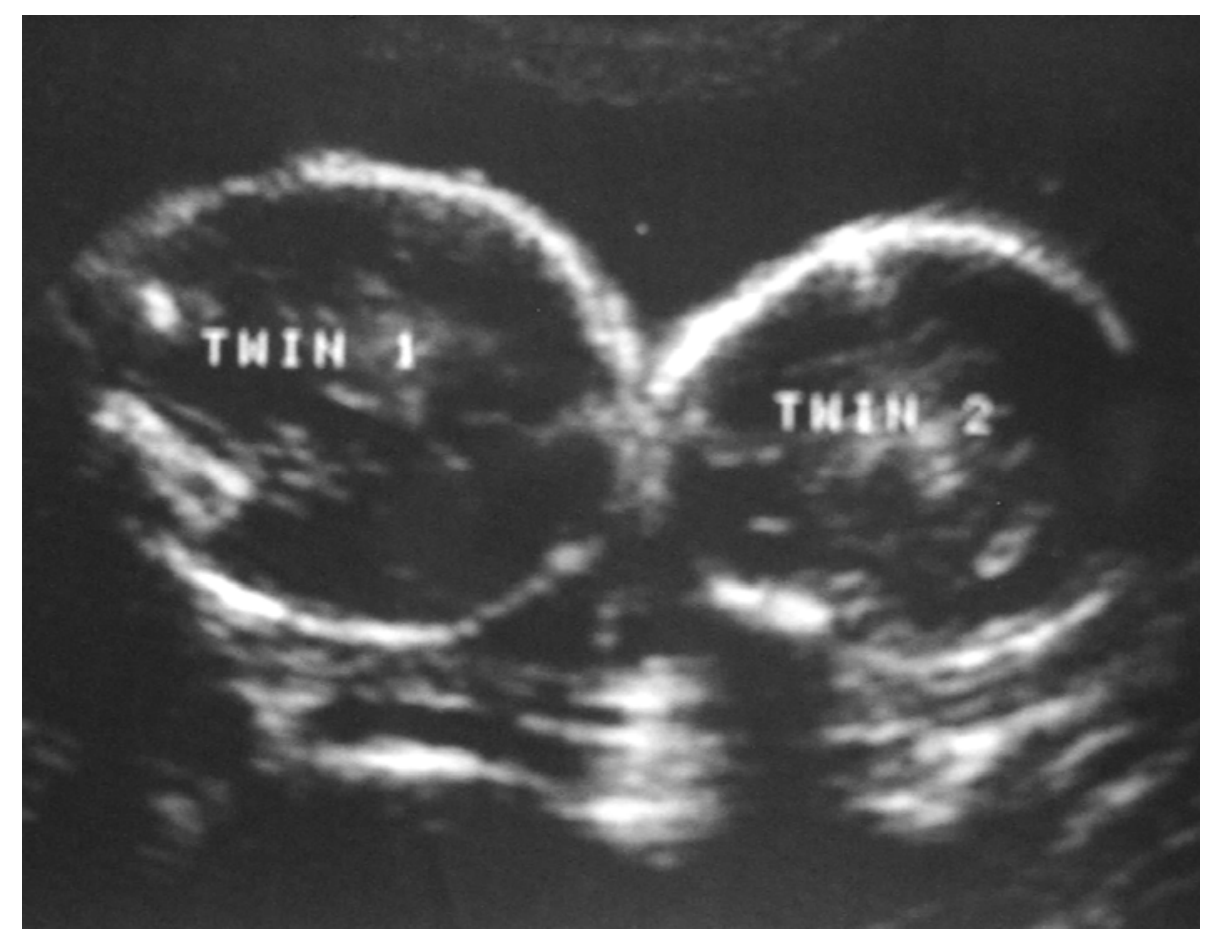

Figure 2: $\quad$ Sonogram of the cephalic presenting twin fetuses.

Twin II was also cephalic presenting but had no associated abnormalities. fetus was essentially normal. The estimated gestational age using femur length was 24 weeks plus 5 days for Twin 1, and 25 weeks for Twin II. A diagnosis of multiple gestations with suspected encephalocele in Twin 1 was made.

Patient was seen regularly at the ante-natal clinic and booked for elective caesarean section at 37 weeks gestational age. At birth, Twin 1 weighed $2.5 \mathrm{~kg}$ and the APGAR score at 1 minute was 6 and at 5 minutes was 10 . Twin 2 weighed $2.7 \mathrm{~kg}$ and the APGAR score was 5 for 1 minute and 8 for 5 minutes. The suspected encephalocele was confirmed on physical examination of the neonate (Twin 1) at Caesarean Section. Immediate post-natal period was uneventful. Plain skull radiograph was requested which showed a soft tissue mass overlying a flattened basiocciput, with uniform opacity. Though the skull defect was not adequately demonstrated, there was an acute angle between the mass and the skin line of the neck and occiput. (Figure 3)

The neonate (Twin 1) was then referred to the Neuro-surgeons for proper evaluation and further management. The patient was lost to follow-up.

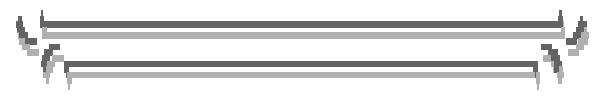




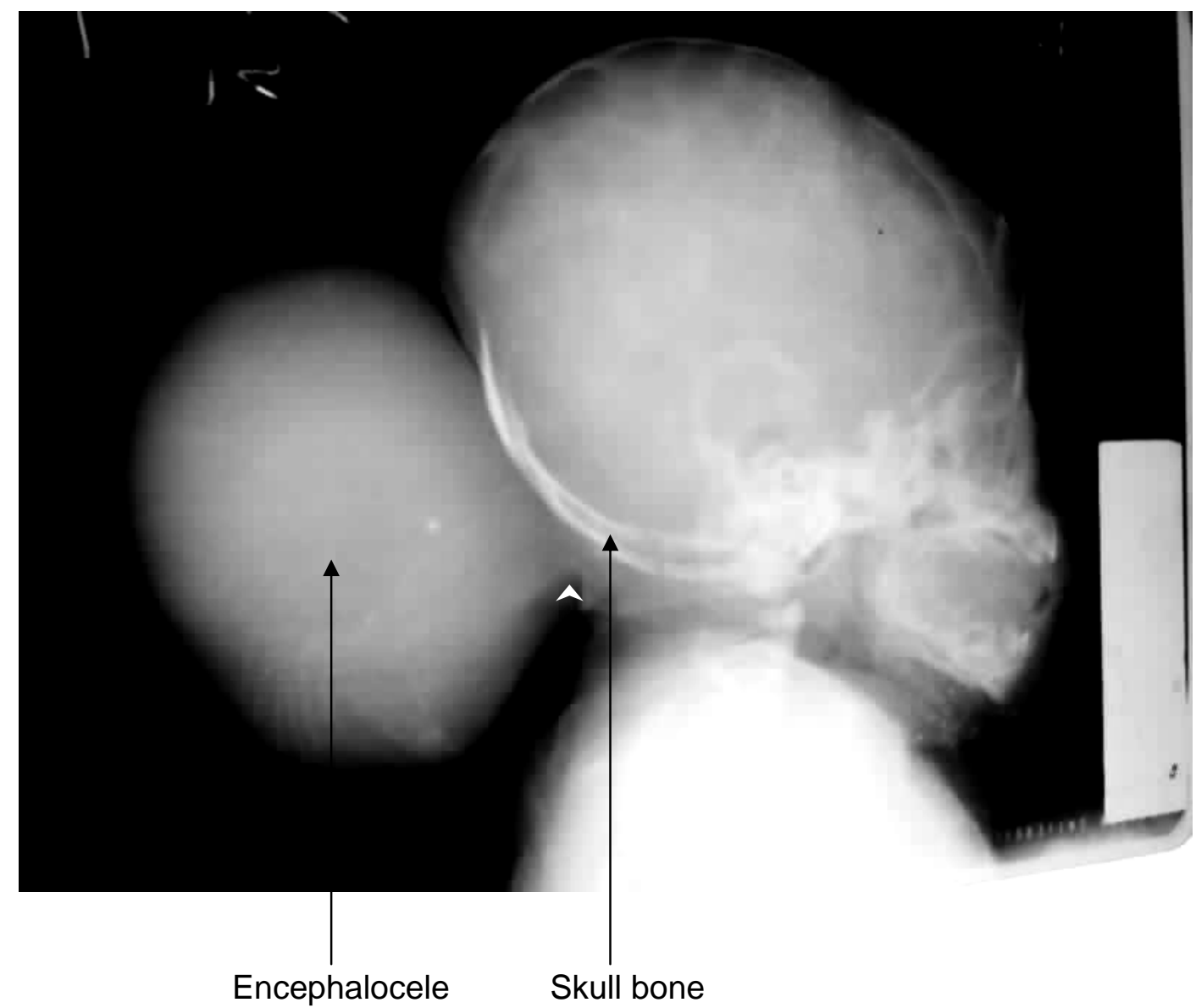

Figure 3: Lateral radiograph of the neonatal skull showing a soft tissue mass overlying a flattened basi-occiput, with uniform opacity. Though the skull defect is not adequately demonstrated, there is an acute angle between the mass and skin line of the neck and occiput.

\section{DISCUSSION}

Encephaloceles are commonly located in the midline and arise in the occipital region in about $75 \%$ of cases. Lateral or parietal encephaloceles occur in about $10-12 \%$, anterior fontanelle or fronto-ethmoidal encepheloceles present in about $13-15 \%$, or less than $5 \%$ in the base of the skull or meninges. Encephaloceles involving the meninges may extend inferiorly and often present as masses in the naso-pharynx or neck. In rare instances, one may encounter orbital encephelocele; in such cases, the sphenoid bone is defective and brain
(White

arrow)

tissue protrudes into the orbit to form sphenoidal encepheloceles (6\%). ${ }^{4-7}$ Encephaloceles usually are readily apparent both clinically and radiologically. The bulging soft tissue and underlying calvarial defect are characteristic as seen in this fetus at sonography. ${ }^{3}$ There is a high association of encephalocele with spina bifida in about $7.3 \%$ of cases. Corpus callosum dysgenesis, ArnoldChiari malformation, Dandy-walker malformation, Meckel-Gruber Syndrome, Amniotic band syndrome, migration abnormalities and chromosomal anomalies in $40 \%$, 
especially trisomy 18 are also associated features. Others are meningo-myeloceles or meningoceles of the spine and vesico-ureteral reflux. ${ }^{5-7,12}$ The case presented however did not demonstrate any such associated anomalies.

It may be ultrasonographically difficult to differentiate occipital encephalocele from cystic hygroma, teratoma, scalp oedema, haemangioma, brachial cleft cyst, and cloverleaf skull in the prenatal period. ${ }^{7}$ The prognosis is dependent on associated malformations, size and contents of the lesion. Twenty-one percent of cases result in live births with 50\% survival rate in live births. Twenty-five percent of these have associated risk of Meckel's syndrome. ${ }^{8}$

Computerized Tomography is useful, but Magnetic Resonance Imaging is best for demonstrating brain tissue in the encephaloceles. ${ }^{3,9}$ In the frontal region, it is of some importance to determine whether the encephalocele is naso-frontal or naso-ethmoidal, for this information facilitates proper neurosurgical correction. . $^{3,9}$

Anomalies occur with a greater frequency in twin gestations. Due to its multifactorial inheritance, twins are usually discordant for encephalocele. However, monoamniotic twins concordant for encephalocele occur with extreme rarity. ${ }^{10-11}$ The importance of prenatal diagnosis of occipital encephalocele in this patient helped in the planning for an elective caesarean surgery, which reduced infant morbidity and mortality.

\section{CONCLUSION}

A 38 year old gravida 14 female, diagnosed sonographically to have an occipital encephalocele in one of the twin fetus at about 24 weeks gestational age is presented.

\section{REFERENCES}

1. Mordic MT. Normal Anatomy. In Mordic MT, Masarykn KJ, Ross JS (Eds). Magnetic Resonance Imaging of the Spine. Year book Medical Publishers, Chicago. 1989; 35-74.

2. Grossmann CB, Post JD. The Adult Spine. In Gonzalez CF, Grossmann CB, Masdeu JM (Eds) Head and Spine Imaging. John Wiley and Sons, New York. 1985; 781-858.

3. Byrd SE, Havwood-Nasl DL, Fitz CR.: Computed Tomography in the evaluation of encephaloceles in infants and children. J Comput Assist Tomogr. 1978: 7: 81-87.

4. Haverson G, Bailey IC, Kiryabwire JWM: The radiological diagnosis of anterior encephaloceles. Clin Radiol. 1974: 25:317 - 322.

5. Yokota A, Matsukada Y, Fuwa I. Anterior basal encephelocele of the neonatal and infantile period. Neurosurgery 1986; 19: $468-478$.

6. Mohay G, Kardos M. Association of occipital encephalocele with vesicoureteral reflux. Orv Hertil 2006; 1: 33-35.

7. Schey EC, Selker RG: Anterior fontanelle

meningoencephalocele. Report of a case. Radiology. 1972, 104: $79-80$.

8. Swischuk LE, Imaging of the Newborn, Infant and YoungChild. Williams and 
Wilkins, Baltimore. 1999: 935 941.

9. Norman D. The spine. In BrantZawadzki M, Norman D (Eds) Magnetic Resonance Imaging of the Central Nervous System. Raven Press, New York. 1987; 289-328.

10. Djientcheu Vde $P$, Wonkam A, Njamnshi KA, Ongolo-Zogo $P$, Rilliet $B$, Morris MA. Discordant encephalocele in monozygotic twins. Am J Med Genet A 2006; 140: 525-526.
11. Ertunc D, Tok EC, Kaplanoglu $\mathrm{M}$, Polat A, Aras N, Evruke C. Concordant occipital encephalocele in monoamniotic twins. J Perinat Med 2005; 33: 357-359.

12. Adetiloye VA, Dare FU, Oyelami OA. A Ten Year Review of Encephalocele in a Teaching Hospital. Int J Gynaecol Obstet 1993; 3: 241-9.

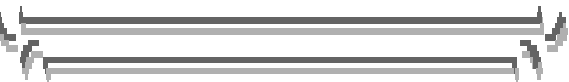

